\title{
Use of homologous and heterologous gene expression profiling tools to characterize transcription dynamics during apple fruit maturation and ripening
}

Fabrizio Costa ${ }^{1,6^{*}}$, Rob Alba ${ }^{2}$, Henk Schouten ${ }^{4}$, Valeria Soglio ${ }^{5}$, Luca Gianfranceschi ${ }^{5}$, Sara Serra ${ }^{1}$, Stefano Musacchi ${ }^{1}$, Silviero Sansavini ${ }^{1}$, Guglielmo Costa', Zhangjun Fei ${ }^{2,3}$, James Giovannoni ${ }^{2,3}$

\begin{abstract}
Background: Fruit development, maturation and ripening consists of a complex series of biochemical and physiological changes that in climacteric fruits, including apple and tomato, are coordinated by the gaseous hormone ethylene. These changes lead to final fruit quality and understanding of the functional machinery underlying these processes is of both biological and practical importance. To date many reports have been made on the analysis of gene expression in apple. In this study we focused our investigation on the role of ethylene during apple maturation, specifically comparing transcriptomics of normal ripening with changes resulting from application of the hormone receptor competitor 1-Methylcyclopropene.
\end{abstract}

Results: To gain insight into the molecular process regulating ripening in apple, and to compare to tomato (model species for ripening studies), we utilized both homologous and heterologous (tomato) microarray to profile transcriptome dynamics of genes involved in fruit development and ripening, emphasizing those which are ethylene regulated.

The use of both types of microarrays facilitated transcriptome comparison between apple and tomato (for the later using data previously published and available at the TED: tomato expression database) and highlighted genes conserved during ripening of both species, which in turn represent a foundation for further comparative genomic studies.

The cross-species analysis had the secondary aim of examining the efficiency of heterologous (specifically tomato) microarray hybridization for candidate gene identification as related to the ripening process. The resulting transcriptomics data revealed coordinated gene expression during fruit ripening of a subset of ripening-related and ethylene responsive genes, further facilitating the analysis of ethylene response during fruit maturation and ripening.

Conclusion: Our combined strategy based on microarray hybridization enabled transcriptome characterization during normal climacteric apple ripening, as well as definition of ethylene-dependent transcriptome changes. Comparison with tomato fruit maturation and ethylene responsive transcriptome activity facilitated identification of putative conserved orthologous ripening-related genes, which serve as an initial set of candidates for assessing conservation of gene activity across genomes of fruit bearing plant species.

\footnotetext{
* Correspondence: fabrizio.costa@iasma.it

1 Department of Fruit Tree and Woody Plant Science, University of Bologna, Viale Fanin 46, 40121 Bologna, Italy

Full list of author information is available at the end of the article
} 


\section{Background}

Fruit are important components in the human diet, serving as sources of vitamins, minerals, fiber and antioxidants [1,2]. In some parts of the world including equatorial regions of Asia, Africa and Americas, fruits can be among the most significant source of limiting nutrients and food security.

During the final stages of development, fruit undergo the unique process of ripening which is often characterized by dramatic changes in color, texture, flavor and aroma, that are controlled by both external signals (light, temperature, hydration) and endogenous hormonal and genetic regulators that render the fruit organ attractive and palatable for seed-dispersing organisms [3].

Based on ripening physiology, apple and tomato are classified as climacteric fruit, in which the onset of ripening is accompanied by a rapid increase in respiration rate, normally coincident with elevated ethylene biosynthesis $[4,5]$. Ethylene is a gaseous hormone able to trigger and coordinate many physiological and response processes in higher plants, including ripening. In climacteric fruits where the hormone typically plays major regulatory roles $[6,7]$, it has been shown that ethylene dependent and independent events operate in tandem to regulate overall ripening $[8,9]$.

The fact that apple and tomato are climacteric suggests that at least some of the regulatory aspects of ripening in both species may be conserved. Tomato has served as a primary model of ripening research due to its short life cycle, ease of transformation, well characterized germplasm http://tgrc.ucdavis.edu/ and availability of extensive molecular resources http://solgenomics. net; http://ted.bti.cornell.edu/; http://www.pgb.kazusa.or. $\mathrm{jp} / \mathrm{kaftom} /$. In this regard it is an optimal reference system for comparative genomics of climacteric ripening with apple.

In an effort to define comprehensive transcriptome variation with the final aim of identifying candidate ripening genes important for apple and conserved among climacteric species, we employed an expression profiling strategies using both heterologous (HET: tomato) and homologous (HOM: apple) expression platforms. The HET array TOM1 was specifically constructed for functional study in tomato http://ted.bti. cornell.edu/cgi-bin/TFGD/array/home.cgi, while the $\mathrm{HOM}$ array was dedicated for apple analysis as a component of the HiDRAS EU-project http://www.hidras. unimi.it. Microarray technology has received enormous emphasis in recent years by the scientific community, due to its capabilities of analyzing transcription activity in a high throughput fashion [10], especially in those species where large amounts of gene sequence are available [11]. We chose to study the ripening process of apple performing a biological assay with an heterologous tomato array because of its large and well detailed collection of genomic information, and because of the success of a similar approach described in both vertebrate species [12] and plants [13,14].

This study aimed to improve knowledge about ripening control in apple by identifying new elements involved in this process, keeping in mind that the use of a heterologous cDNA array is limited to those genes that retain a minimal degree of sequence homology. However, a similar phenomena occurs in cDNA homologous array hybridization, due to the cross hybridization of members belonging to the same gene family characterized by high sequence similarity [15]. The use of TOM1 was justified by its greater coverage, while the value of the HOM apple array was grounded in the fact that this is a fruit dedicated array, already used to identify genes differentially expressed during fruit development and maturation in apple [16], and in this context represented a valuable tool to confirm the heterologous data. The use of a common reference genomic tool is an attractive prospect for analysis of non-model plants. The two platforms were simultaneously assessed to characterize fruit ripening transcription dynamics with an emphasis on ethylene-regulated genes.

Earlier high-throughput genomic efforts on fruit ripening and quality have been reported by several groups, with the first being Aharoni et al. who identified genes related to strawberry fruit quality [17]. With regards to prior transcriptomics studies on tree fruit species, the peach microarray $\mu \mathrm{PEACH} 1.0$ was used to study gene expression changes associated with the transition from pre-climacteric to climacteric fruit development [18], while in nectarine it was used to elucidate transcriptome variation in response to the ethylene perception inhibitor 1-MCP [19].

Apple has been investigated with a small number of microarray platforms, though most are of limited size, or more focused on fruit development and pre-harvest ripening [20-23].

Large scale statistical analysis of ESTs in apple have been reported, including an in silico comparison with tomato [24,25]. Gene expression comparisons between apple and tomato, two fleshy-fruited species belonging respectively to the Rosaceae and Solanaceae, could be very informative in unraveling the unique and common determinants of ripening control. Tomato has been widely used as the primary model species for climacteric fruit ripening $[1,8,26]$, and a comprehensive transcriptomic tool kit has been developed to analyze the underlying genetic ripening network. Alba et al. [27,28] described extensive time-series expression profiling of wild-type tomato fruit using the TOM1 array (also used here with apple). In this work [28], 869 of approximately 9,000 genes assayed were differentially expressed during 
the fruit maturation process, $37 \%$ of which were altered in comparison with the Never ripe ethylene receptor mutant [29].

Here we report our exploration of ethylene dependent and independent trascriptomics of apple fruit maturation and ripening as compared to tomato. The apple ethylene transcriptome was further characterized in the context of the response caused by the ethylene perception competitor 1-Methylcyclopropene (1-MCP) [30]. We present a comprehensive biological cross-species genomic comparison between apple and tomato, using and comparing homologous and heterologous cDNA microarrays in addition to 2-dimensional protein separation, to highlight conserved and unique gene activities contributing to the complex and important mechanism of climacteric ripening control.

\section{Methods \\ Plant material and characterization of fruit ripening physiology}

Mondial Gala fruit were harvested at commercial ripening, and a subset of 40 fruits were treated overnight with $1 \mathrm{ppm}$ of $1-\mathrm{MCP}$ at $24^{\circ} \mathrm{C}$ in sealed containers. Ethylene production was monitored by gas-chromatography (DANI, Monza, Italy), on five fruits, three times/week per two fruit batches, analyzed for 10 and 60 days, respectively, after harvest. In these two time-course experiments, ethylene was measured for both control and treated sample in order to profile a normal evolution compared to the kinetics affected by the ethylene competitor (1-MCP).

Samples were also assessed for fruit firmness with a digital firmness tester (equipped with a $11 \mathrm{~mm}$ probe) on the two peeled and opposite fruit surfaces of each fruit tested. Transcriptome profiling was carried out with RNA isolated from seven tissues (collected from the first batch) with three biological replicas for each (total 21 samples). Three time-points spanned early fruit maturation: green (66 DAFB - days after full blossom), breaker (90 DAFB), and red ripe (114 DAFB, also the time of the typical commercial harvest), and four timepoints spanned late ripening stages: $\mathrm{T} 1_{\mathrm{Ctrl}}(120 \mathrm{DAFB})$ $\mathrm{T} 22_{\mathrm{Ctrl}}(123 \mathrm{DAFB})$ for the control, and the two corresponding $1-\mathrm{MCP}$ treated samples: $\mathrm{T} 1_{1-\mathrm{MCP}}$ and $\mathrm{T} 2_{1-\mathrm{MCP}}$. The experimental design is thus characterized by two time courses, with the first spanning climacteric ripening (green-breaker-red ripe- $\mathrm{T} 1_{\mathrm{Ctrl}}-\mathrm{T} 2_{\mathrm{Ctrl}}$ ) and the second the same but as influenced by $1-\mathrm{MCP}$ treatment (greenbreaker-red ripe- $\left.\mathrm{T} 1_{1-\mathrm{MCP}}-\mathrm{T} 2_{1-\mathrm{MCP}}\right)$.

RNA isolation and HET (heterologous) - HOM (homologous) expression profiling in apple fruit

Total RNA was isolated from liquid nitrogen frozen flesh (stored at $-80^{\circ} \mathrm{C}$ ) collected from all stages, using a CTAB- based extraction buffer [31]. After the first precipitation the procedure followed the protocol reported in the TED database http://ted.bti.cornell.edu/cgi-bin/TFGD/array/ total_RNA_extraction.cgi and modified [32].

Synthesis and cDNA labelling were performed according to [27]. First-strand synthesis and purification was obtained with the Super-Script ${ }^{\text {tw }}$ Indirect cDNA Labelling System Kit (Invitrogen Corp), and microarray hybridization was performed labelling the cDNA with $\mathrm{Cy} 3$ for the reference and Cy5 for the experimental test samples. Labelling and hybridization protocols are detailed in the TED database http://ted.bti.cornell.edu/cgi-bin/ TFGD/array/total_RNA_label.cgi; http://ted.bti.cornell. edu/cgi-bin/TFGD/array/TOM1_hybridization.

cgi $[33,34]$. Our experimental design employed a common reference design, hybridizing three biological replicates for each time point [35].

\section{Data Processing}

Microarray slides were processed using a two-channel confocal scanner (ScanArray 5000) and the images were acquired and analyzed with ScanArray v3.1 software (Packard Biochip Technologies), setting the PMT at 65$75 \%$, with a scanning resolution of $10 \mu \mathrm{m}$. Raw images files were captured and converted to intensity values using Imagene software (v5.6. Bio-Discovery Inc., El Segundo, CA, USA). Data analysis was performed using BRB-Array Tools 3.4 http://linus.nci.nih.gov/BRB-ArrayTools.html, an integrated software package based on R statistic developed by Dr. Richard Simon and Amy Peng Lam [36]. Data were transformed to the $\log _{2}$ scale and normalized with the lowess methods to minimize systematic variance. Differentially expressed genes (DEGs) over the time course were identified using the class comparison tool, performing a paired sample $\mathrm{t}$-test $(\mathrm{P}$ value $<0.01)$. The multiple variation tests were used with the maximum false discovery rate set at 0.1 and $90 \%$ of confidence.

Expression profile clustering was conduced with the GEPAS web-based resource for microarray gene expression analysis (Gene Expression Profile Analysis Suite, http://gepas.bioinfo.cipf.es [37]). Comprehensive heterologous and homologous data were clustered using the SOTA algorithm (Self Organising Tree Algorithm), an unsupervised neural network with a binary tree topology [38]. Overall graphical representation of the total heterologous transcriptome data was visualized using MATLAB 6.0 (The MathWorks). Microarray data are available in the Array Expression database http://www.ebi.ac.uk/ microarray-as/ae/ with the number A-MEXP-1867.

\section{Quantitative Real Time PCR for gene specific expression profiling}

From the seven samples, five $\mu \mathrm{g}$ of total RNA/sample was used to reverse transcribe cDNA using Superscript 
II Reverse Transcriptase (Invitrogen Technology) with Oligo $\mathrm{dT}_{25}$. Real Time PCR was carried out with $\mathrm{SYBR}^{\circ}$ Green PCR Master Mix (Applied Biosystem) using the following primers related to ACO and PG genes: RTMd-ACO1_for: CAGGCAACGACGCATTCAT, RTMd-ACO1_rev: GGCGTCCCCAGTTTTCTTCT and RT-Md-PG1_for: ACCGGTGGGATAGCAACATC, RTMd-PG1_rev: ATTCCCTTTAGCTCCAAAATCGT. Amplicon detection was performed using an ABI Prism 7700 Sequencing Detection System with the following thermal profile: $95^{\circ} \mathrm{C}$ for $10^{\prime}$ and subsequent 40 cycles of $95^{\circ} \mathrm{C}$ for $15 \mathrm{sec}, 60^{\circ} \mathrm{C}$ for $1 \mathrm{~min}$ and $48^{\circ} \mathrm{C}$ for $30 \mathrm{sec}$. Amount of target was normalized to an endogenous reference (18S) and expressed as $2^{-\Delta \Delta C t}$ (Applied Biosystem, User Bulletin \#2).

\section{D Proteomic analysis}

Total protein extraction used two grams of frozen cortex collected from two samples of Mondial Gala apple: $\mathrm{T} 1_{\mathrm{Ctrl}}$ and $\mathrm{T} 1_{1-\mathrm{MCP}}$. The extraction buffer contained 500 $\mathrm{mM}$ Tris- $\mathrm{HCl}$ (pH 8), $700 \mathrm{mM}$ sucrose, $10 \mathrm{mM}$ EDTA, $4 \mathrm{mM}$ ascorbic acid, $1 \mathrm{mM}$ PMSF, $0.2 \%$ Triton X-100, 1 $\mu \mathrm{M}$ leupeptin and $100 \mathrm{mM}$ Pefabloc. Sample were solubilized in $7 \mathrm{M}$ urea, $2 \mathrm{M}$ tiourea, $2 \% \mathrm{w} / \mathrm{v}$ CHAPS, $2 \%$ w/v Triton X-100, 2\% w/v ampholytes IPG buffer (3-10 $\mathrm{pH}$ range), $5 \% \mathrm{w} / \mathrm{v}$ DTT and a trace of bromophenol blue. The first dimension was carried out on an Ettan IPGphor I (Amersham Bioscience) at $70 \mathrm{KVs}$. The strips were subsequently equilibrated for $12 \mathrm{~min}$ in $50 \mathrm{mM}$ Tris- $\mathrm{HCl}(\mathrm{pH} 6,8), 6 \mathrm{M}$ urea, $30 \% \mathrm{v} / \mathrm{v}$ glycerol, $2 \% \mathrm{w} / \mathrm{v}$ SDS and $2 \% \mathrm{w} / \mathrm{v}$ DTT; and for an additional $5 \mathrm{~min}$ in $50 \mathrm{mM}$ Tris- $\mathrm{HCl}$ (pH 6,8), $6 \mathrm{M}$ urea, 30\% v/v glycerol, $2 \% \mathrm{w} / \mathrm{v}$ SDS and $2,5 \% \mathrm{w} / \mathrm{v}$ iodacetamide and a trace of bromophenol blue. After equilibration, the strips were placed on $12.5 \%$ polyacrylamide gels $(26 \mathrm{~cm} \times 20 \mathrm{~cm} \times$ $1 \mathrm{~mm}$ ) in the Ettan Dalt Six Electrophoresis system (Amersham Bioscience), and the second dimension was carried out at $12 \mathrm{~mA} /$ gel over-night at $10^{\circ} \mathrm{C}$. Gel images were analyzed using the Image Master Platinum v.5.0 Software (Amersham Bioscience). Spot matching was performed using two synthetic gels by overlapping three gels per sample and placing 23 anchors in each gel.

\section{Results and Discussion}

\section{Transcriptome dynamics in apple fruit}

Transcriptome analysis was performed by hybridizing all samples comprising the experimental design (Figure 1) on both the TOM1 and apple arrays containing 12,899 and 1,608 ESTs, respectively (Additional file 1). The total expression data set, represented by 9,663 filtered and normalized features, was organized into two structured SOTA clusters, comparing functional dynamics between normal fruit ripening and that altered by 1MCP in the following stages: green (66 DAFB), breaker
(90 DAFB), red ripe (114 DAFB), T1 $1_{\mathrm{Ctrl} / 1-\mathrm{MCP}}(120$ DAFB) and T2 $2_{\text {trrl/1-MCP }}(123$ DAFB). To highlight the functional differences between control and 1-MCP treatment, the entire expression regime was re-plotted considering only the last stages of the experimental design (red ripe as the reference point, $\mathrm{T} 1_{\mathrm{Ctrl} / 1-\mathrm{MCP}}$ and $\mathrm{T} 2_{\mathrm{Ctrl} /}$ $1-\mathrm{MCP}$ ) focusing on the regulatory effects resulting from the ethylene response inhibitor treatment (Figure 2a and Additional file 2). Four clusters were isolated from the SOTA tree organization with two down- and two upregulated profiles during normal ripening (Figure $2 \mathrm{~b}$ ). Within these profiles was the transcriptomic variation caused by 1-MCP (Figure 2c) impacting genes involved in hormone biosynthesis/response, cell wall metabolism, transcription and secondary metabolism (Figure 2d). Similar results in terms of classes of annotated genes were also obtained employing the HOM array. In this case the general profile was represented within a hierarchical clustering (Figure 3a), revealing that the 1-MCP impact on general ripening was similar to that detected with the HET array (Figure 3b, c and 3d).

Gene expression dynamics were analyzed over the climacteric time course using a permutation-based pairedsample t-test performed with BRB-Array Tools, which identified 652 DEGs (Differentially Expressed Genes) in the HET data set (Additional file 3) and 139 DEGs using the HOM array (Additional file 4). In silico crossspecies nucleotide sequence alignment was performed comparing the total set of 7,352 annotated tomato unigenes comprising TOM1 with the public apple EST collection http://www.rosaceae.org. General similarity analysis was performed via Blastn with a cut-off value of $1 \times 10 \mathrm{e}^{-5}$. In this analysis, $52 \%$ of the genes were considered homologous, as defined by a nucleotide sequence identity greater than $75 \%$ (Figure 4). Out of 652 differentially expressed HET array unigenes associated with apple ripening, 430 matched to a corresponding apple sequence with an identity value higher than the $75 \%$ considered necessary for designation as "homologous" (Additional file 5). This analysis yielded results similar to what was reported in a prior Solanaceae cross species analysis, where $75 \%$ of the available sequences of pepper and eggplant were homologous with those on the tomato array [39]. While apple is more distant from tomato than other members of the Solanaceae, it is noteworthy that the TOM1 array was weighted toward fruit development related genes and these sequences may be more conserved among climacteric fruits. The comparison between tomato and Arabidopsis revealed a lower identity value, further supporting the hypothesis that the TOM1 array might be enriched for conserved fruit-associated genes and thus for using the tomato array as a reference for gene expression studies in fleshy fruits. Apple is a fleshy, climacteric, indehiscent fruit 
a
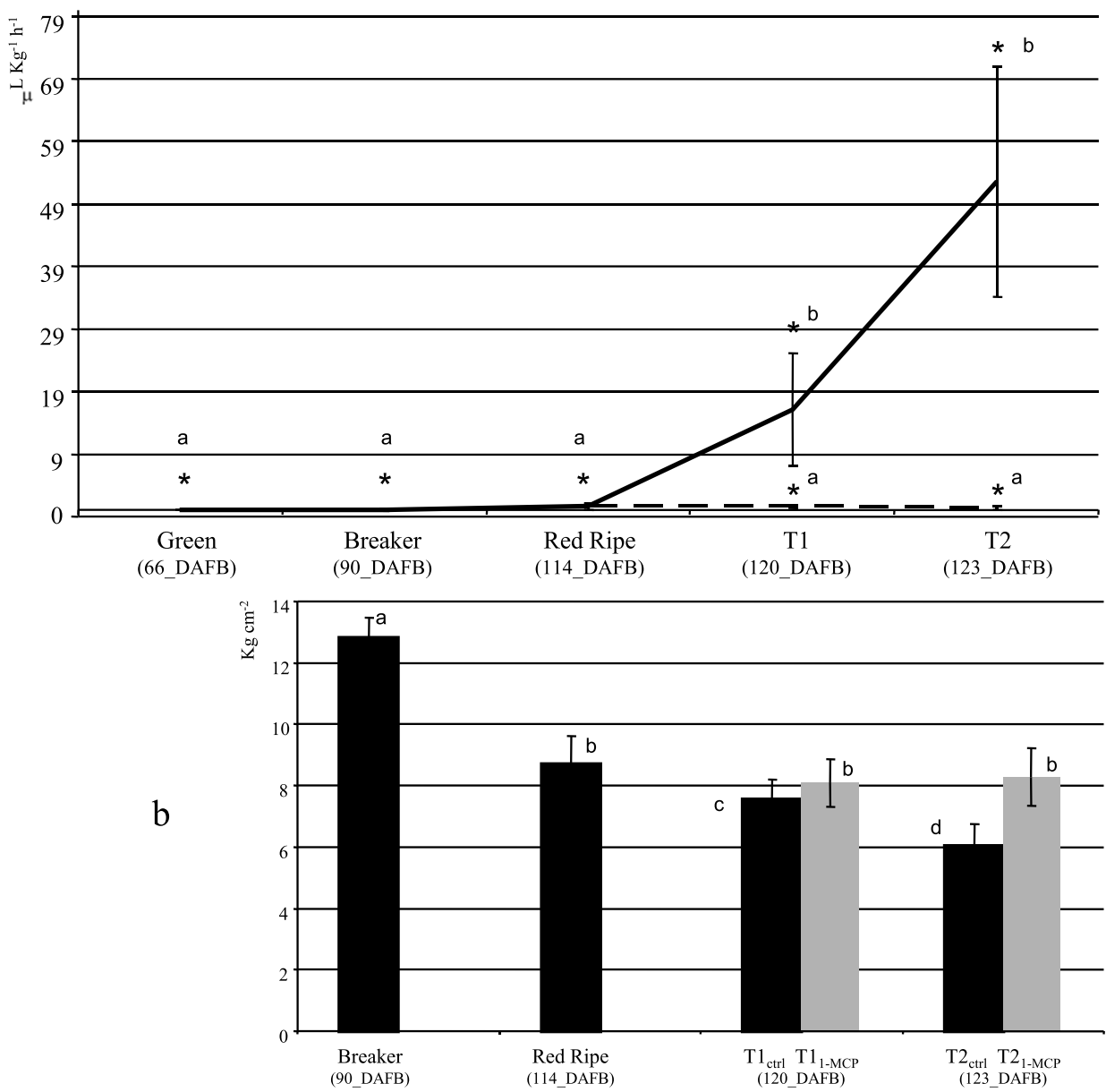

Microarray experimental design

Time point 1

Fruit stage: Green

DAFB: 66

Time point 2

Fruit stage: Breaker

DAFB: 90

Time point 3

Fruit stage: Red Ripe

DAFB: 114

Time point 4

Fruit stage: T1_Ctrl

DAFB: 120

Time point 5

Fruit stage: T1 1-MCP

DAFB: 120

Time point 6

Fruit stage: T2_Ctrl

DAFB: 123

Time point 7

Fruit stage: T2_1-MCP

DAFB: 123

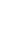

CP




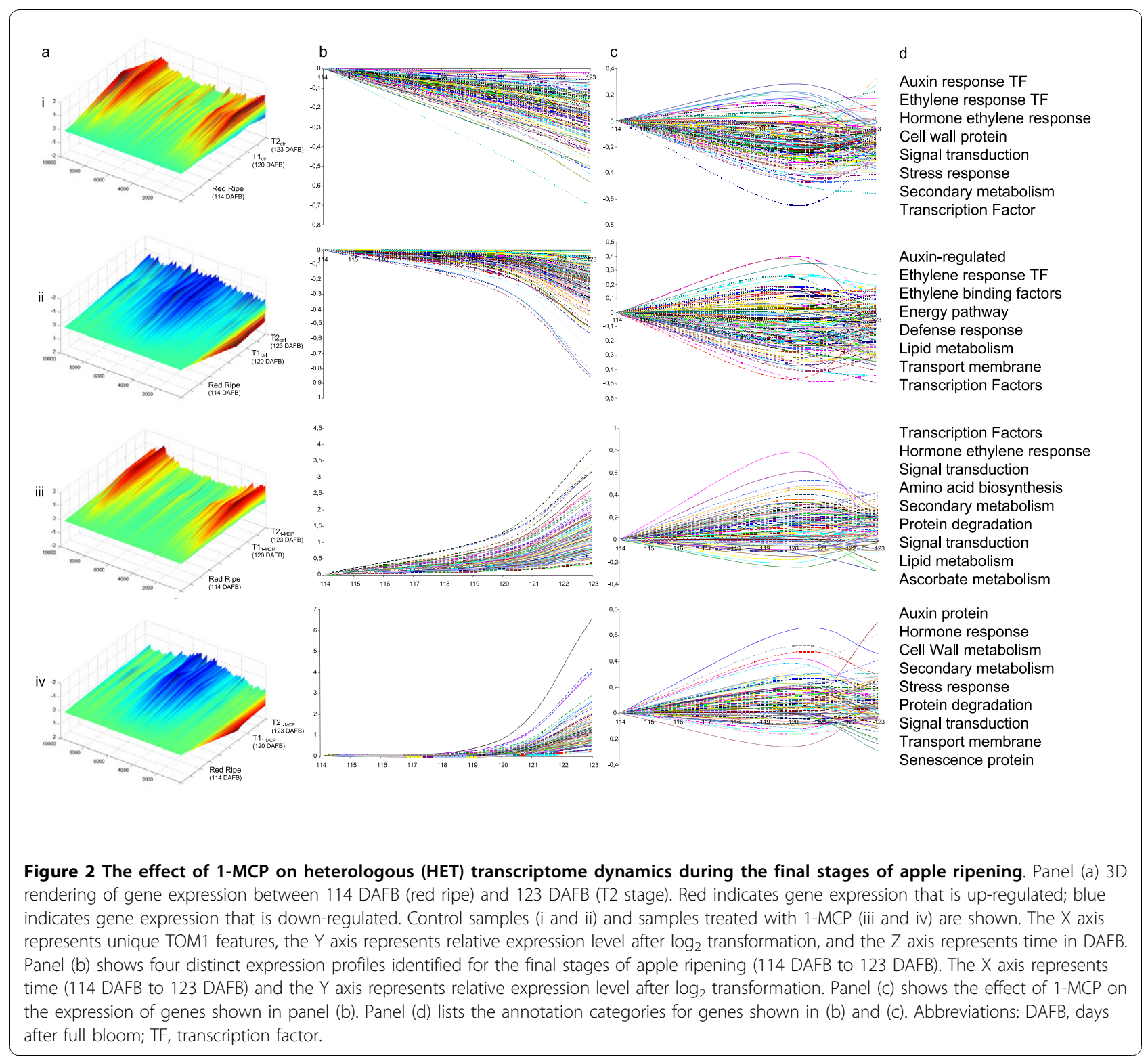

treated, respectively. 1-MCP treatment revealed 358 unique spots, corresponding to $37.8 \%$ of the total protein pattern. The difference in the percentage of impacted genes versus proteins likely reflects the fact that the proteomics analysis we performed is likely to over-emphasize the more abundant structural proteins and under-represent the less abundant regulatory peptides suggesting that a greater number of low abundance and putative regulatory proteins may be impacted by 1 MCP. Alternatively (or in addition) this discrepancy may reflect the fact that multiple gene family members may encode proteins that cannot be distinguished via the 2$\mathrm{D}$ analysis. More comprehensive proteomics analysis that results in peptide identification would be required to sort out these or other possibilities.
The number of genes and proteins observed to be impacted by $1-\mathrm{MCP}$ treatment is indeed quite significant especially considering that in this work the 1 -MCP treatment occurred at harvest (114 DAFB) when ripening is well underway. In the HOM array we observed a higher rate of genes influenced by $1-\mathrm{MCP}$, but it must be noted that while the HET array is enriched for fruit-related sequences [27] the HOM array is a fully fruit dedicated array, and thus even more genes than in the HET array would be anticipated to display differential expression during ripening and as a consequence of 1-MCP treatment. It is also interesting that we observed an approximately equal ratio of genes either positively or negatively regulated by ethylene, demonstrating that ethylene in apple has an important and complex impact on ripening physiology, 


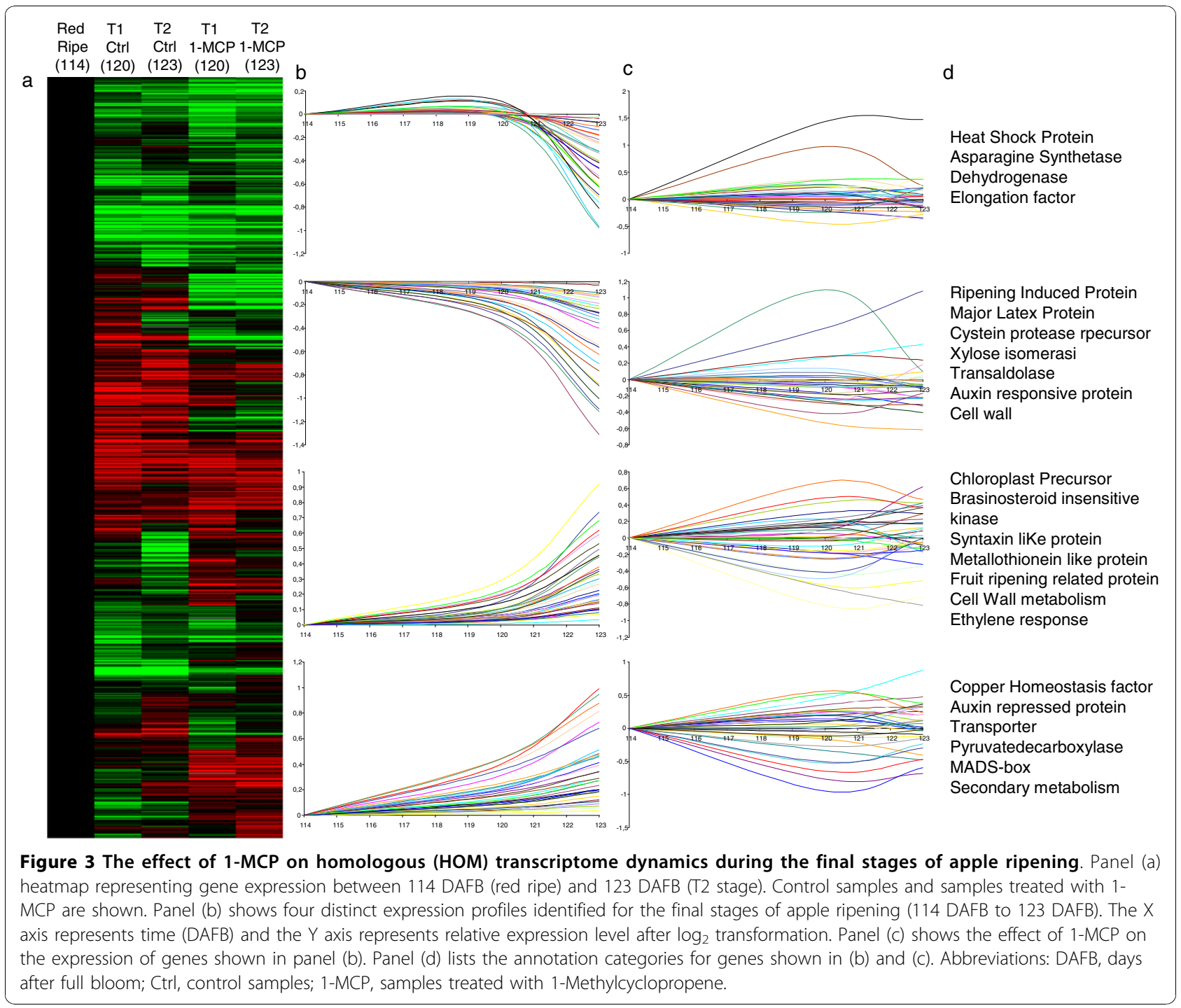

regulating both positively or negatively the expression of various genes. Even more interesting is the fact that a considerable number of ripening-related genes were not affected by the hormone, indicating ethylene-independent ripening mechanisms in climacteric apple fruit. Such genes may be especially interesting as candidates for common regulatory control between climacteric and non-climacteric fruits and thus represent a unique set of genes for further investigation. Ethylene dependent and independent genes have been previously reported in melon [9] where it was suggested that in at least some cases members of the same gene family were regulated under these two distinct ripening control processes [40].

\section{Transcriptional control of ethylene synthesis, perception and signalling in apple}

Mondial Gala fruit development was characterized at three distinct physiological stages: (i) green (66 DAFB, days after full bloom), (ii) breaker (90 DAFB) and (iii) red ripe (114 DAFB). Fruit ripening initiation was defined by the induction of ethylene starting from red ripe $\left(0.65 \mu \mathrm{Kg}^{-1} \mathrm{~h}^{-1}\right)$ and increasing at $\mathrm{T} 1_{\mathrm{Ctrl}}(120 \mathrm{DAFB})$ and $\mathrm{T} 2_{\mathrm{Ctrl}}(123 \mathrm{DAFB})$, producing $16.11 \mu \mathrm{Kg}^{-1} \mathrm{~h}^{-1}$ and $52.57 \mu \mathrm{lKg}^{-1} \mathrm{~h}^{-1}$ of ethylene respectively. Following harvest, 1-MCP application resulted in reduced ethylene synthesis with an ethylene synthesis rate of only $0.66\left(\mathrm{~T} 1_{1-\mathrm{MCP}}\right)$ and $0.42 \mu \mathrm{lKg} \mathrm{K}^{-1} \mathrm{~h}^{-1}$ (for $\mathrm{T} 22_{1-\mathrm{MCP}}$ ), or a reduction in ethylene synthesis of greater than $90 \%$ (Figure 1a). To further investigate the efficacy of 1-MCP ethylene repression, we performed a second ethylene assessment extended to 60 days after harvest. At the end of this period the maximum ethylene production in the 1-MCP treated sample was similar to the control (Figure 5), but with a shift of 21 days. Specifically, the control sample produced its maximum $\left(129.53 \mu \mathrm{Kg}^{-1} \mathrm{~h}^{-1}\right)$ after 26 days following harvest (140 DAFB), while the treated produced $112.12 \mu \mathrm{Kg}^{-1} \mathrm{~h}^{-1}$, but 


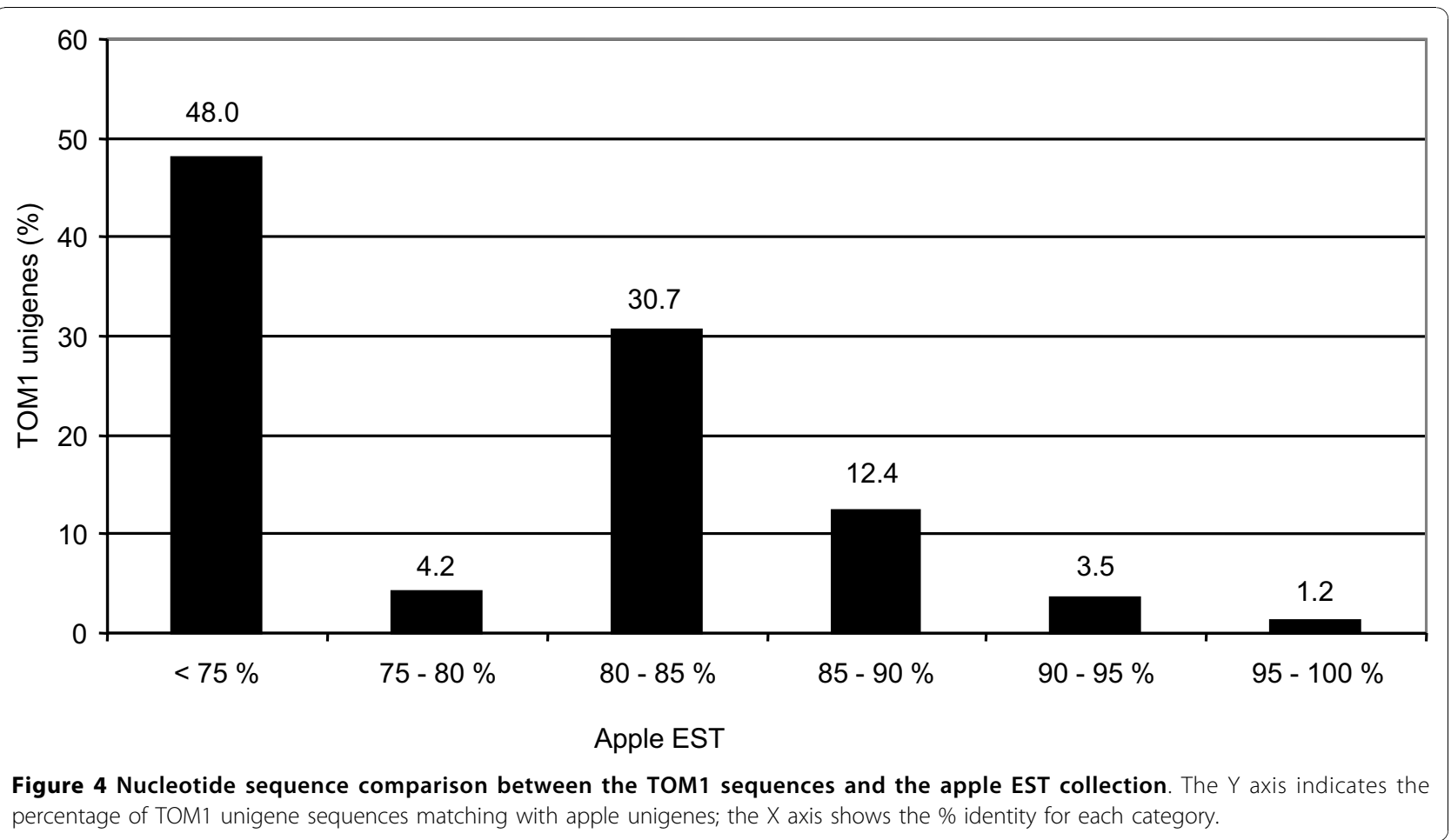

at day 47 (161 DAFB). These two maximum amounts of ethylene were not statistically different (ANOVA/LSD test, $\mathrm{P}=0.05$ ).

HET microarray analysis identified a set of hormonerelated DEGs whose expression was differentially coordinate by ethylene. During fruit development, genes involved in the auxin biosynthetic pathway (aux1 protein: SGN-U215673, auxin regulated protein: SGNU215773, aux protein: SGN-U218763) showed their maximum transcript accumulation at breaker stage (Figure 6 and Additional file 9). A similar elevated expression trend was also observed for genes involved in ethylene response including an ethylene inducible protein (SGN-U214488) and ethylene responsive element (ethylene responsive protease inhibitor I: SGN-U217278, EREBP: SGN-U213917). The TOM1 (HET) data highlighted the ethylene dependent transcriptional control which was additionally supported by 1-MCP application as reflected in down regulation of genes involved in ethylene synthesis and signal transduction which are normally highly expressed during the ethylene burst and include such genes as: SAM 1-2-3 (S-adenosylmethionine synthase: SGN-U212824, SGN-U213593, SGNU212955), ACS (1-aminocyclopropane-1-carboxylate synthase: SGN-U213523), ACO (1-aminocyclopropane1-carboxylate oxidase: SGN-U212787), EIL (ethylene insensitive like; SGN-U214759), EREBP (ethylene responsive element binding factors: SGN-U213917) and
ERF3 (ethylene responsive factor: SGN-U214815) genes. ERFs are especially interesting as they have documented roles in regulating ethylene responsive genes [41,42], and an ethylene dependent gene expression was confirmed previously through 1-MCP application in apple by Wang et al. [43]. Identification of differentially expressed genes in the ethylene synthesis pathway and cell wall metabolism was also considered validation of the utility of the heterologous array platform. Thus, to additionally confirm HET microarray validity, we assessed the expression of $\mathrm{ACO}$ and PG, two genes involved in ethylene biosynthesis and cell wall metabolism (ethylene regulated), respectively, via qPCR in apple. We also interrogated the TED database for tomato in silico digital expression profiles (Additional file $10 \mathrm{a}$ and $\mathrm{b}$ ). In both cases the expression was consistent with that observed in HET and HOM profiling. Specifically, positive regulation at the onset of climacteric ripening and down-regulation upon ethylene inhibition (1-MCP application in apple or analysis of the $\mathrm{Nr}$ mutation in tomato). We note that in this comparison our main limitation was alignment of the apple and tomato developmental time courses where in tomato the ethylene burst occurs at the breaker stage (42 DAP, days after pollination in cv. Ailsa Craig), while in apple this is a post-harvest phenomena. Nevertheless, in the case of the ACO and PG controls, maximum gene expression was coincident with the hormone burst and declined 

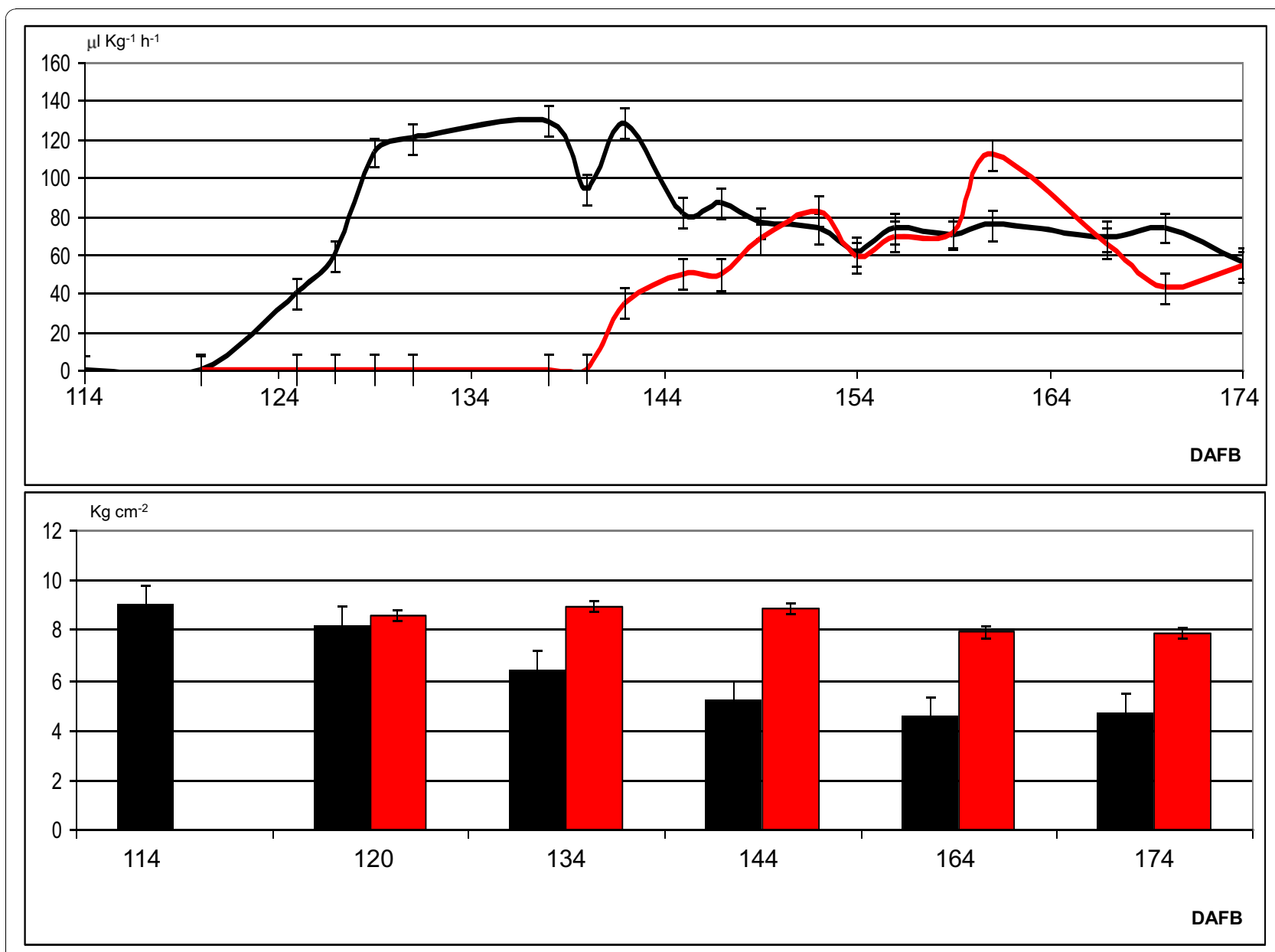

Figure 5 Ethylene biosynthesis and softening of Mondial Gala apple after 60 days of post-harvest ripening at ambient temperature. The upper panel shows ethylene evolution during fruit maturation and ripening. The black and red lines indicate ethylene released by control samples and the samples treated with 1-MCP, respectively. Standard error bars are shown. The lower panel shows fruit softening during maturation and ripening. Black and red bars indicate the control samples and the samples treated with 1-MCP, respectively. Standard error bars are shown. Abbreviations: DAFB, days after full bloom.

thereafter in both species and with both the HOM and HET arrays suggesting a degree of reliability in both platforms.

In the gene set negatively correlated with climacteric ethylene production (represented by $21 \%$ of DEGs) we identified hormone-related genes associated predominantly with plant growth rather than ethylene with the best hits to members involved in auxin (aux/IAA: SGNU218763, SGN-U219594) and gibberellin (gibberellin 2-oxidase: SGN-U214290, SGN-U216196) response pathways. Furthermore, in the HOM array we identified seven genes putatively involved in hormone signalling networks. Three were homologous to regulatory genes of the auxin pathway, while the other four were involved in ethylene biosynthesis and signalling: ACO, ethylene receptor and Md-ETR genes (Additional file 11). The expression of both ACO and Md-ETR was ethylene dependent, as both were up-regulated during normal ripening and repressed by $1-\mathrm{MCP}$.

\section{Transcriptional control of fruit softening in apple}

To establish ties between gene expression pattern and fruit physiology, we analyzed a number of ripening parameters in the same fruit used for expression profiling including measurement of fruit firmness (Figure 1b). Firmness in $\mathrm{T} 1$ fruit was $7.5 \mathrm{Kg} \mathrm{cm}^{-2}$ for the control and $8.1 \mathrm{Kg} \mathrm{cm}^{-2}$ for the 1-MCP treated samples and this difference increased in fruit at the T2 stage, with $6 \mathrm{Kg}$ $\mathrm{cm}^{-2}$ for $\mathrm{T} 22_{\mathrm{Ctrl}}$ and $8.3 \mathrm{Kg} \mathrm{cm}^{-2}$ for T2 1 -MCP, respectively. 1-MCP treated samples lost only $1.2 \mathrm{Kg} \mathrm{cm}^{-2}$ after 60 days of post-harvest ripening, compared to the $4.4 \mathrm{Kg} \mathrm{cm}^{-2}$ lost by the control (Figure 5).

Using the HET array we identified 27 DEGs putatively involved in cell wall metabolism (Additional file 3). We 


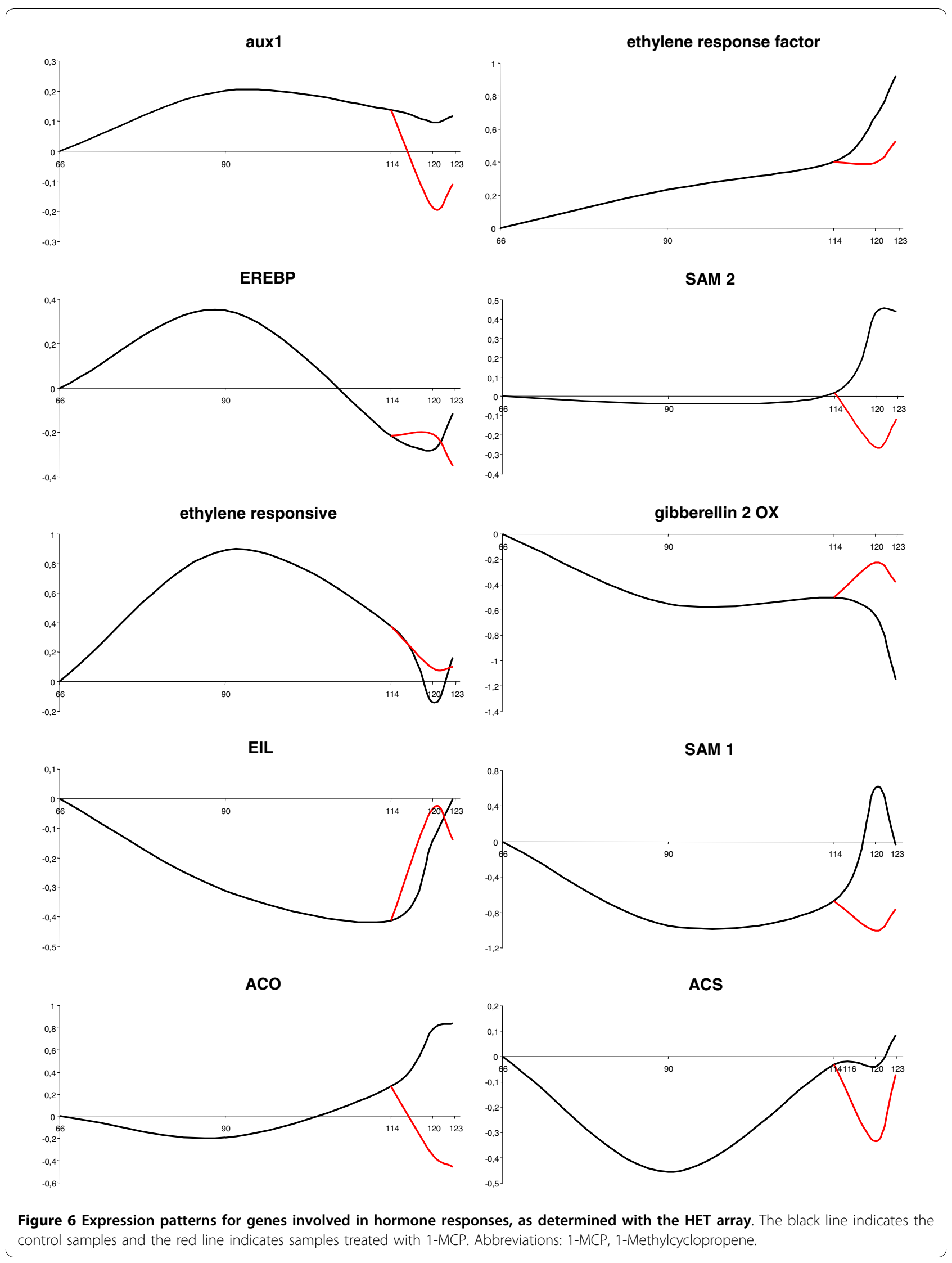


observed two general trends of gene expression related to cell wall enzymes (Figure 7 and Additional file 9b). The first trend comprise a set of genes whose maximum expression occurs in the breaker/red ripe stages and then decreases during the post-harvest period, such as pectin acetylesterase (SGN-U217232), cellulose synthase (SGN-U221500), chitinase (SGN-U217904) and extensin (SGN-U214487). The second category is characterized by genes whose maximum transcript abundance is observed at the end of the time course, coincident with the ethylene burst in apple. Transcripts of xyloglucan endotransglycosylases (SGN-U215860), xyloglucan endo 1-4 glucanase (SGN-U217975) and polygalacturonase (SGN-U213213) fall into this category. Our data regarding cell wall gene expression profiling was consistent with the results of others [44-46] reporting both early and late fruit development enzymatic actions associated with fruit softening. Among the genes involved in later stage cell wall metabolism, polygalacturonase, xyloglucan endotransglycosylases and xyloglucan endo 1-4 glucanase, in particular, showed down regulation after 1 -MCP treatment, confirming the importance of ethylene and cell wall metabolizing enzymes in fruit softening control. In the HOM array seven cell wall unigenes demonstrated differential expression (Additional file 12) including pectin acetylesterase precursor, endoxyloglucan transferase, xylose isomerase and a polygalacturan gene. According to the HET profile, polygalacturonase found on the HOM array showed an ethylene dependent profile as well, with a maximum release at $\mathrm{T} 2_{\mathrm{Ctrl}}$, and strong down-regulation following 1-MCP treatment.

\section{Transcription factor gene expression in fruit maturation and ripening}

Fruit development and ripening are highly coordinated by an emerging set of transcription factors which have been defined largely in tomato though shown to have counterparts in other climacteric and non-climacteric species [47-51]. Using TOM1, $11.5 \%$ of the differentially expressed genes during fruit development and ripening

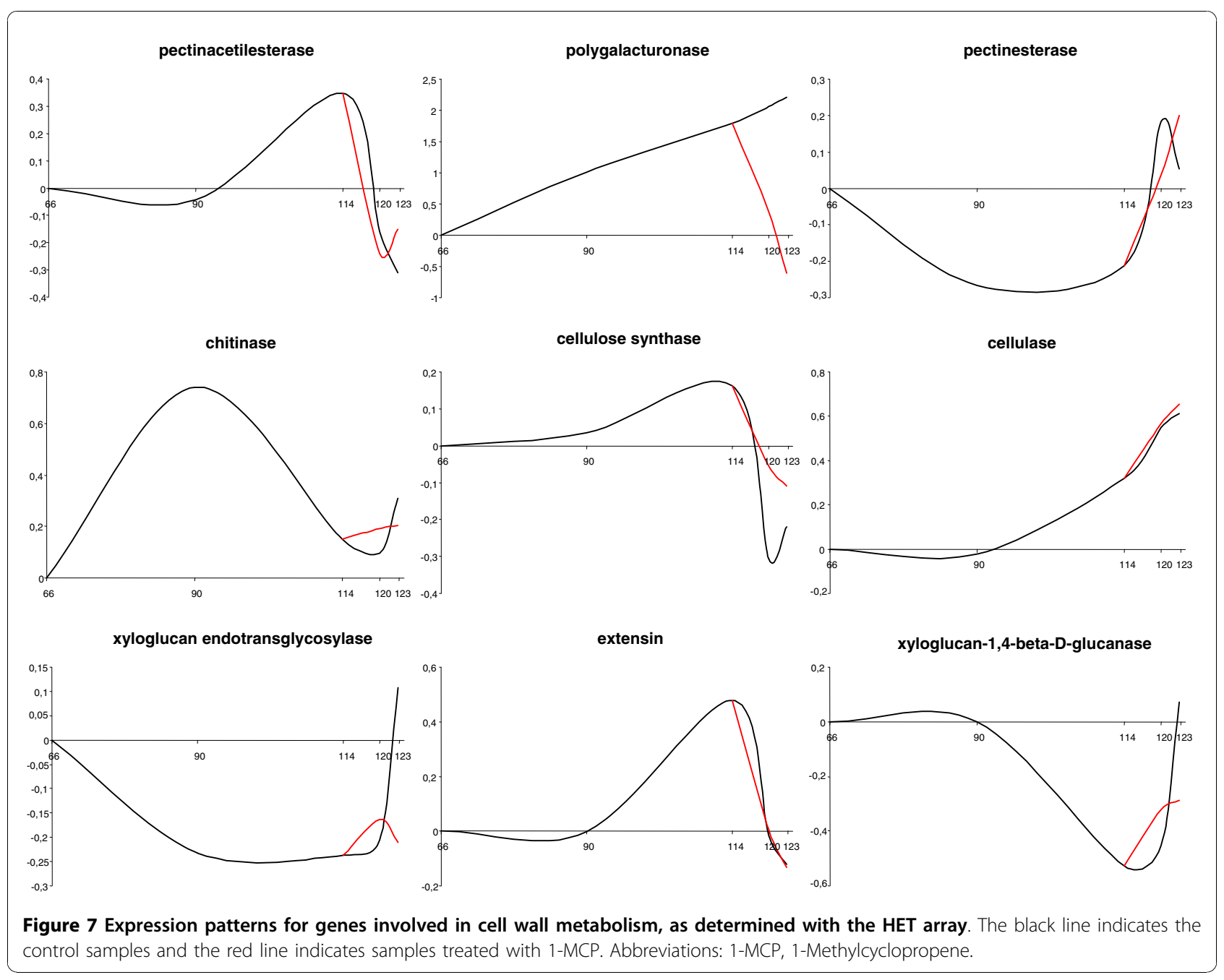


were annotated as putative transcription factors, and $40 \%$ of these were up regulated in the preclimacteric phase (between green and red ripe), while the majority were highly expressed at the onset of ripening (from red ripe to the T2 stage), as typical in tomato [3]. Within this category, the most common gene families were MYB, AP2 domain, bZIP, MADS-box, bHLH and WIZZ, a set of transcription factors which are generally the most abundant in all eukaryote genomes sequenced to date [52].

1-MCP application affected the expression of $13 \%$ of these transcription factor genes (Additional file 9c). Unigenes belonging to the bZIP (SGN-U214146) group and WIZZ (SGN-U213245) were down regulated by 1-MCP treatment (ethylene dependent), while other elements including MADS-box GDEF1 (SGN-U215918), MYB TMH27 (SGN-U215971) and AP2 (SGN-U218041) genes were stimulated by this treatment, suggesting negative regulation by ethylene in a subset of putative ripening regulators (Figure 8). Five AP2 members were identified in the HET array, both developmentally and ripening regulated, in agreement with observations in peach [18].

Transcription factors that showed the highest change in mRNA abundance between the breaker and red ripe stages included bell-like (SGN-U214635), CCR4 (SGN-U213840), jasmonic acid 1 (SGN-U214021), Pti5 (SGN-U217388), YABBY2 (SGN-U213463), MYB (SGN-U215971, SGNU215897), SET domain (SGN-U225149), ZPT2 (SGNU213138), bZIP (SGN-U220645, SGN-U220052), bHLH (SGN-U223789) and AP2 (SGN-U219020). In addition to those induced during fruit development, others showed a unique profile of being primarily specific to ripening/ethylene expression such as homeodomain (SGN-U213729), bZIP (SGN-U214147), Dof-zinc (SGN-U218870), TINY (SGN-U224037), WRKY (SGN-U212725, SGN-U245688, SGN-U214107), WIZZ (SGN-U213245) and NAM (SGNU220043). Transcription factors belonging to AP2, bHLH, bZIP, homeobox, MADS, MYB and the squamosa families showed complex and unique fruit development and ripening regulation, with different members of these families induced in both periods. The role of bZIP in fruit ripening has been documented in other species such as watermelon [53], tomato [54] and strawberry [55]. In climacteric fruits the role of MADS-box genes has been previously confirmed in tomato via demonstration of the necessity of LeMADS-RIN for ripening [49] and of MdPI in apple seed and fruit development [51]. The relevance of this family in these physiological processes was also supported by interaction studies where 5 MADS-box elements including TDR4 were shown to interact in vitro with LeMADS-RIN $[1,56]$. In the current HOM apple data set only two transcription factors have been identified (Additional file 13): a leucine rich repeats (LRR) protein, and a MADS box gene further supporting the value of the HET data developed here. Both genes were positively regulated by ethylene. 1-MCP application caused dramatic repression of both genes further supporting the role of ethylene in the regulation of these genes.

To have a better picture of fruit transcriptomics, the entire HOM transcription profile was organized in a functional dendrogram which revealed two main clusters (Additional file 14). The 1-MCP treated samples clustered in a group closer to the earlier pre-ripening developmental stages (green and breaker). In fact, within this DEG group were identified elements typical of organs in development, involved in energy biosynthesis, nucleic acid metabolism and transcriptional control. By this functional correlation it is evident that during fruit development and ripening the change between the breaker and ripening stage are determined in large part by differential gene expression.

Together with ethylene receptors, transcription factors represent key developmental timing systems [57]. A delayed ethylene burst due to 1-MCP could induce the plant to activate compensatory regulatory machinery in order to re-establish normal ripening physiology. Extending the fruit post-harvest observation up to 60 days after harvest we have in fact observed that the sample treated with 1-MCP reached almost the same maximum amount of ethylene suggesting such feed back control mechanisms operate during ripening.

Conserved expression dynamics in apple and tomato fruit One of our primary objectives was to add to the reservoir of ripening knowledge by identifying genes co-associated with ripening and ethylene response in both tomato and apple. Toward this end we compared the 652 genes differentially expressed in this work with the 869 tomato homologous genes reported by Alba et al. [28]. Comparison of these two data sets (detected with the same platform: TOM1), identified 157 genes common to both data sets. Of these, 108 genes had apple orthologous sequence counterparts with higher than $75 \%$ identity, representing a putative gene set of homologs involved in the ripening of both species (Table 1 and Additional file 15). A similar number of genes (102) differentially expressed over the course of fruit development of both apple and tomato was reported by Janssen et al. [23], however, only $20 \%$ of these genes were identified in this study so that a new and larger collection of highly homologous ripeningassociated genes is available from tomato and apple. Such genes represent a foundation from which candidate conserved genes among other fruit species can be mined. The major differences with the Janssen report were likely due to the differences between experimental designs. In their case the samples collected where more representative of the pre-ripening fruit development and initial 


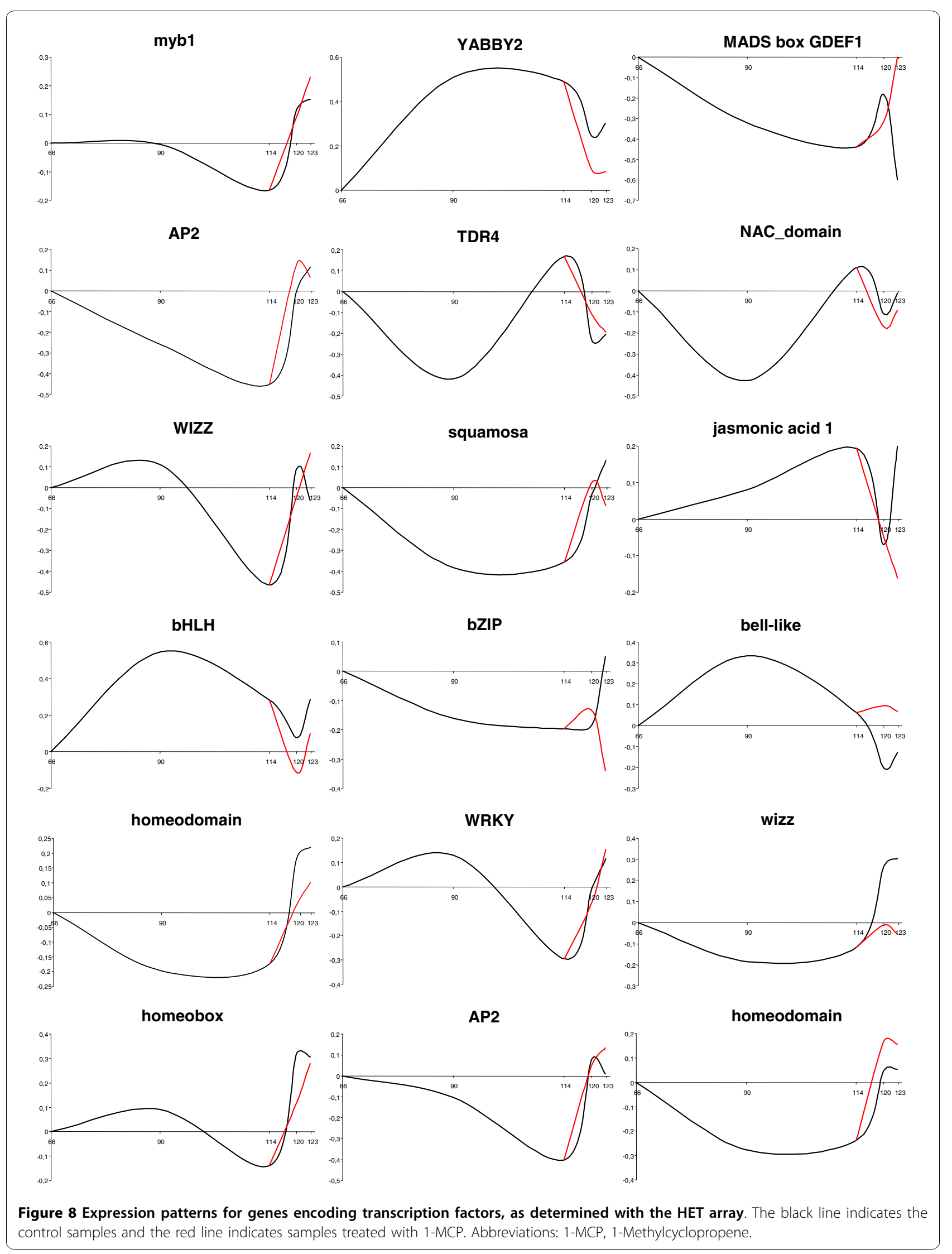


Table 1 Apple and Tomato Ripening Genes

\begin{tabular}{|c|c|c|}
\hline Tomato_ID & Apple_ID & Gene_annotation \\
\hline & & cell wall; carbohydrate metabolism; cell wall degredation; fruit softening \\
\hline SGN-U212775 & CN29021 & pectate lyase [Malus $x$ domestica] \\
\hline SGN-U217975 & CN25519 & xyloglucan endo-1,4-beta-D-glucanase (EC 3.2.1.-) precursor (clone tXET-B2) - tomato \\
\hline SGN-U213213 & CN14797 & Polygalacturonase 2A precursor (PG-2A) (Pectinase) \\
\hline \multirow[t]{2}{*}{ SGN-U213444 } & CN27677 & xyloglucan endotransglycosylase (XTR4), putative [Arabidopsis thaliana] \\
\hline & & defense responses; disease resistance; pathogenesis; wound induced \\
\hline \multirow[t]{2}{*}{ SGN-U219296 } & CX022916 & ELI3 [Lycopersicon esculentum] \\
\hline & & hormone responses; auxin responses; IAA responses \\
\hline \multirow[t]{2}{*}{ SGN-U215673 } & CN7981 & axi 1 protein from Nicotiana tabacum -related [Arabidopsis thaliana] \\
\hline & & hormone responses; ethylene responses \\
\hline SGN-U214488 & CN24915 & ETHYLENE-INDUCIBLE PROTEIN HEVER \\
\hline SGN-U212804 & CN445336 & ACC oxidase homolog (Protein E8) \\
\hline \multirow[t]{2}{*}{ SGN-U214815 } & CN28691 & ethylene response factor 3 [Lycopersicon esculentum] \\
\hline & & hormone responses; ethylene biosynthesis \\
\hline SGN-U212786 & CN309 & ACC oxidase, 1-aminocyclopropane-1-carboxylate oxidase 1 (ACC oxidase 1) \\
\hline SGN-U212787 & CN27 & ACC oxidase, 1-aminocyclopropane-1-carboxylate oxidase 1 (ACC oxidase 1) \\
\hline SGN-U214919 & CN309 & ACC oxidase, 1-aminocyclopropane-1-carboxylate oxidase [Solanum tuberosum] \\
\hline SGN-U216896 & U73815 & ACC synthase, 1-aminocyclopropane-1-carboxylate synthase 2 \\
\hline SGN-U212824 & CN1498 & S-adenosylmethionine synthetase 1 \\
\hline SGN-U212955 & CN14011 & S-adenosylmethionine synthetase 3 \\
\hline \multirow[t]{2}{*}{ SGN-U213593 } & CN1498 & S-adenosylmethionine synthetase 2 \\
\hline & & ripening-related \\
\hline \multirow[t]{2}{*}{ SGN-U213072 } & CN5470 & ripening-related protein [Vitis vinifera] \\
\hline & & transcription factor \\
\hline SGN-U213245 & CO052409 & WIZZ [Nicotiana tabacum] \\
\hline SGN-U213317 & CN791 & transcription factor BTF3 (RNA polymerase B transcription factor 3) \\
\hline SGN-U213318 & CN791 & transcription factor BTF3 (RNA polymerase B transcription factor 3) \\
\hline SGN-U213318 & CN791 & transcription factor BTF3 (RNA polymerase B transcription factor 3) \\
\hline SGN-U213659 & CN27467 & TDR4 transcription factor [Lycopersicon esculentum] \\
\hline SGN-U213840 & CN26889 & CCR4-associated factor -related [Arabidopsis thaliana] \\
\hline SGN-U215425 & CN8887 & bZIP transcription factor BZI-4 [Nicotiana tabacum] \\
\hline SGN-U215688 & CN25810 & WRKY family transcription factor [Arabidopsis thaliana] \\
\hline SGN-U215971 & CN1890 & myb-related protein $\mathrm{TMH} 27$ - tomato \\
\hline SGN-U217991 & CN495178 & AP2 domain transcription factor, putative [Arabidopsis thaliana] \\
\hline SGN-U219020 & CN495178 & AP2 domain transcription factor, putative [Arabidopsis thaliana] \\
\hline
\end{tabular}

Twenty-eight genes that are differentially expressed in the ripening of apple and tomato (Alba et al., 2005 and Fei et al., 2006), specifically involved in ethylene biosynthesis and response, cell wall metabolism and transcription factors.

maturation, while this work focused on the later development and post-harvest ripening. As such this work focuses on the climacteric stage and the corresponding link with the ethylene production was confirmed through the finding of twelve microarray elements representing genes involved in hormone production and response (SAM, ACS and ACO). In Janssen et al. [23] six genes were defined as ethylene related and all reflected SAM synthase genes, one of the early enzymes in the ethylene biosynthetic pathway. In Janssen et al. [23] five genes were found related to cell wall metabolism in common with tomato, of which two are $\alpha$-expansin, here showed to be more active during the initial fruit softening stage. Our work identified 6 cell wall sequences in common 
with tomato though more related to later stages of fruit softening (e.g. polygalacturonase, xyloglucan endo-1,4 glucanase). The combination of these two data sets improves the common genomic comparison between apple and tomato, expanding the number of possible genes commonly active in both (and presumably other) species from early development through post-harvest ripening.

The heterologous expression profiles of the 108 common genes for apple were compared with tomato in silico digital expression data retrieved from the TED database http://ted.bti.cornell.edu/. Pearson correlation confirmed that over the course of normal climacteric ripening almost $70 \%$ of the genes identified by array analysis were consistent with the digital expression results, again providing validation for the HET array assay in apple and suggesting equally useful results could be recovered from other fruit species to expand the comparative fruit genomics base.

Analyzing the digital expression profile of the common gene set using the WT vs. $\mathrm{Nr}$ tomato comparison, we observed differential expression of $35.7 \%$ of genes, consistent with what was reported by Alba et al. [28]. In apple, for the same gene set identified with the same array, 1-MCP resulted in differential expression of $30 \%$ of these genes, consistent with the tomato results and suggesting that these elements might have a common regulatory role in ripening control of both tomato and apple.

\section{Conclusion}

In this work we presented a heterologous approach to investigate the transcriptome of apple ripening and common genes with tomato that may serve as a base collection of candidates for conserved ripening regulation among diverse fruit species. The HET tomato array was used with the principal goal of identifying candidate genes related to fruit development and ripening that could then be related to previously characterized tomato ripening genes. Gene validation was partially gained by parallel hybridization of the same set of samples with the HOM array (which is apple-specific but of limited size).

Heterologous microarray platforms could provide a useful alternative to explore transcriptome dynamics in the absence of a whole genome array and EST data. Here we have demonstrated the use of a tomato array to identify putative apple sequences which are associated with ripening and thus may be targets for further fruit ripening and comparative genomics studies. At present to the scientific community is presented a growing number of advanced next generation sequencing technologies (NGST) that provide a viable alternative to microarray analysis [58]. Despite their great potential, these new technologies still present some bias mainly related to technical features of the outputs [59] and the need for strong bioinformatics support to exploit these data. With the recent availability of the apple genome [60] and the impending release of the tomato genome, these NGST will certainly open new possibilities to target gene expression with high fidelity such as the repertoire of candidate ripening and evolutionarily conserved fruit genes that can be further expanded between tomato and apple and extended to additional important fruit crop species.

\section{Additional material}

Additional file 1: Comparison between the hybridization of the tomato array (a) and the apple array (b) with apple cDNA. Images (c) and (d) represent the sub-grid magnification for both arrays.

Additional file 2: Comparative dynamics between the control (a) and 1-MCP treated (b) sample. The 3D plot refers to the up regulated profile. In the boxes are highlighted specific genes of the functional profile.

Additional file 3: DE genes in apple identified using the heterologous (HET) array TOM1.

Additional file 4: DE genes in apple identified using the homologous (HOM) apple array.

Additional file 5: TOM1 unigenes homologous to the apple EST dataset collection. Homology is defined by $75 \%$ identity.

Additional file 6: GO annotations for DE genes identified with the HET (a) and HOM (b) arrays. Tables include GO annotations, the number of unigenes identified, and the relative percentage of unigenes identified.

Additional file 7: Comparative dynamics between the control sample (a) and the 1-MCP treated sample (b). The profiles refer to down regulation. In this particular case a negative regulation is reflected into an up regulation in the positive part of the plot (framed box).

Additional file 8: 2D proteomic comparison profile carried out using $\mathrm{T} 1_{\mathrm{Ctrl}}$ and $\mathrm{T} 1_{1-\mathrm{MCP}}$ samples. Each synthetic gel has been obtained from 3 gels per sample. Colored squares represent the anchors used to facilitate the comparison. Data at the bottom of the figure summarize spot numbers and the relative matching values.

Additional file 9: Hierarchical clustering of gene expression patterns identified with the HET array. Three functional categories are shown: hormone pathways (a), transcription factors (b) and cell wall enzymes (c). The three clusters show functional dynamics of late ripening and comparison with 1-MCP. Samples are coded as RR for red ripe: C1 and $\mathrm{C} 2$ for $\mathrm{T} 1$ and T2 Control respectively; M1 and M2 for T1 and T2 1-MCP treated respectively.

Additional file 10: Expression profiles for ACO and PG in apple and tomato. (a) shows expression profiles in developing apple fruit, as determined by $\mathrm{QPCR}$. (b) shows digital expression profiles in tomato fruit, as retrieved from the TED database. Data for ACO and PG are shown in red and black, respectively. The solid line indicates the control samples and the dashed line indicates samples treated with 1-MCP. Abbreviations: DAFB, days after full bloom; DAP, days after pollination; 1-MCP, 1Methylcyclopropene.

Additional file 11: Expression patterns for genes involved in hormone responses, as determined with the HOM array. The black line indicates the control samples and the red line indicates samples treated with 1-MCP. Abbreviations: 1-MCP, 1-Methylcyclopropene.

Additional file 12: Expression patterns for genes involved in cell wall metabolism, as determined with the HOM array. The black line indicates the control samples and the red line indicates samples treated with 1-MCP. Abbreviations: 1-MCP, 1-Methylcyclopropene. 


\section{Additional file 13: Expression patterns for genes encoding} transcription factors, as determined with the HOM array. The black line indicates the control samples and the red line indicates samples treated with 1-MCP. Abbreviations: 1-MCP, 1-Methylcyclopropene.

Additional file 14: Expression clustering dendrogram with centered correlation and average linkage. The cluster was produced using HOM array data and shows the expression profile similarity among samples.

Additional file 15: Eighty genes (complementary to table 1) expressed during the ripening of both apple and tomato

\section{Acknowledgements}

This paper has been carried out with financial support from the Commission of the European Communities, specific research program "Quality of Life and Management of Living Resources", QLRT-2001-01492 "High-quality Disease Resistant Apples for a Sustainable Agriculture". It does not necessarily reflect its views and in no way anticipates the Commission's future policy in this area. The authors thank Sara Stella for qPCR assay. The author thanks the reviewers for providing stimulating and constructive comments to the manuscript.

\section{Author details}

1 Department of Fruit Tree and Woody Plant Science, University of Bologna, Viale Fanin 46, 40121 Bologna, Italy. ${ }^{2}$ Boyce Thompson Institute for Plant Research, Cornell University Campus, Ithaca, New York, 14853, USA. ${ }^{3}$ U.S. Department of Agriculture, Agricultural Research Service, Robert W. Holley Center, Ithaca, New York, 14853, USA. ${ }^{4}$ Plant Breeding, Wageningen-UR, Droevendaalsesteeg 1,6700 AA Wageningen, The Netherlands. ${ }^{5}$ Dept. of Biomolecular Sciences and Biotechnology, University of Milano, via Celoria 26, 20133 Milano, Italy. ${ }^{6}$ IASMA Research and Innovation Centre, Foundation Edmund Mach, Via E. Mach 1, 38010 San Michele all'Adige, Trento, Italy.

\section{Authors' contributions}

FC designed the experiment, collected the samples, performed the microarray hybridization, analyzed the data and wrote the manuscript. RA supported the microarray hybridization, contributed to the data analysis and revised the manuscript. HS provided the apple array. VS and LG supported the interpretation and annotation of the homologous array. SSerra and SM performed the 2-D proteomic assay. SSansavini supported the sample collection. GC supported the 1-MCP treatment and gas-chromatography analysis for ethylene. ZF performed the bioinformatics analysis. JG contributed to the experiment design, provided important advise during the work and improved the manuscript.

All authors read and approved the final manuscript.

Received: 22 April 2010 Accepted: 25 October 2010

Published: 25 October 2010

\section{References}

1. Giovannoni JJ: Genetic regulation of fruit development and ripening. Plant Cell 2004, 16:S170-S180.

2. Lelièvre J-M, Latché $A$, Jones $B$, Bouzayen $M$, Pech J-C: Ethylene and fruit ripening. Physiologia Plant 1997, 101:727-739.

3. Bartley GE, Ishida BK: Developmental gene regulation during tomato fruit ripening and in-vitro sepal morphogenesis. BMC Planty Biol 2003, 3:4.

4. Yang SF, Hoffman NE: Ethylene biosynthesis and its regulation in higher plants. Annu Rev Plant Physiol 1984, 35:155-189.

5. Alexander L, Grierson D: Ethylene biosynthesis and action in tomato: model for climacteric fruit ripening. J Ex Bot 2002, 53:2039-2055.

6. Barry CS, Llop-Tous MI, Grierson D: The regulation of 1Aminocyclopropane-1-Carboxylic Acid Synthase gene expression during the transition from system-1 to system-2 ethylene synthesis in tomato. Plant Physiol 2000, 123:979-986.

7. White PJ: Recent advances in fruit development and ripening: an overview. J Ex Bot 2002, 53:1995-2000.

8. Giovannoni JJ: Molecular biology of fruit maturation and ripening. Annu Rev Plant Physiol Plant Mol Biol 2001, 52:725-49.
9. Pech JC, Bouzayen M, Latché A: Climacteric fruit ripening: Ethylenedependent and independent regulation of ripening pathways in melon fruit. Plant Sci 2008, 175:114-120.

10. Clarke JD, Zhu T: Microarray analysis of the transcriptome as a stepping stone towards understanding biological systems: practical consideration and perspectives. The Plant J 2006, 45:630-650.

11. Duggan DJ, Bittner $M$, Chen $Y$, Meltzer $P$, Trent JM: Expression profiling using cDNA microarrays. Nat Genet 1999, 21:10-21.

12. Renn SCP, Aubin-Horth N, Hofmann HA: Biologically meaningful expression profiling across species using heterologous hybridization to a cDNA microarray. BMC Genom 2004, 5:42

13. Horvath DP, Schaffer $R$, West M, Wisman E: Arabidopsis microarrays identify conserved and differentially expressed genes involved in shoot growth and development from distantly related plant species. The Plant J 2003, 34:125-134.

14. Bagnaresi $P$, Moschella A, Beretta O, Vitulli F, Ranalli P, Perata P: Heterologous microarray experiments allow the identification of the early events associated with potato tuber cold sweetening. BMC Genom 2008, 9:176.

15. Hammer SL, Kay SL: Microarrays: Determining the balance of cellular transcription. Plant Cell 2000, 12:613-615.

16. Soglio V, Costa F, Molthoff JW, Weemen-Hendriks WMJ, Schouten HJ, Gianfranceschi L: Transcription analysis of apple fruit development using cDNA microarrays. Tree Genet and Gen 2009, 5:685-698.

17. Aharoni A, Keizer LCP, Bouwmeester HJ, Sun Z, Alvarez-Huerta M, Verhoeven HA, Blaas J, van Houwelingen AMML, De Vos RCH, van der Voet $H$, Jansen RC, Guis M, Mol J, Davis RW, Schena M, van Tunen AJ, O'Connell AP: Identification of the SAAT gene involved in strawberry flavor biogenesis by use of DNA microarray. Plant Cell 2000, 12:647-661.

18. Trainotti L, Bonghi C, Ziliotto F, Zanin D, Rasori A, Casadoro G, Ramina A, Tonutti P: The use of microarray $\mu \mathrm{PEACH} 1.0$ to investigate transcriptome changes during transition from pre-climacteric to climacteric phase in peach fruit. Plant Sci 2006, 170:606-613.

19. Ziliotto F, Begheldo M, Rasori A, Bonghi C, Tonutti P: Transcriptome profiling of ripening nectarine (Prunus persica L. Batsch) fruit treated with 1-MCP. J Ex Bot 2008, 59:2781-2791.

20. Fonseca S, Hackler LJ, Zvara A, Ferreira S, Baldé A, Dudits D, Pais MS, Puskás LG: Monitoring gene expression along pear fruit development, ripening and senescence using cDNA microarrays. Plant Sci 2004, 167:457-469.

21. Lee Y-P, Yu G-H, Seo YS, Han SE, Choi YO, Kim D, Mok I-G, Kim WT, Sung S$\mathrm{K}$ : Microarray analysis of apple gene expression engaged in early fruit development. Plant Cell Rep 2007, 26:917-926.

22. Schaffer RJ, Friel EN, Souleyre EJF, Bolitho K, Thodey K, Ledger S, Bowen JH, Ma J-H, Nain B, Cohen D, Gleave AP, Crowhurst RN, Janssen BJ, Yao J-L, Newcomb RD: A genomics approach reveals that aroma production in apple is controlled by ethylene predominantly at the final step in each biosynthetic pathway. Plant Physiol 2007, 144:1899-1912.

23. Janssen BJ, Thodey K, Schaffer RL, Alba R, Balakrishnan L, Bishop R, Bowen JH, Crowhurst RN, Gleave AP, Ledger S, McArtney S, Pichler FB, Snowden KC, Ward S: Global gene expression analysis of apple fruit development from the floral bud to ripe fruit. BMC Plant Biol 2008, 8:16.

24. Newcomb RD, Crowhurst RN, Gleave AP, Rikkerink EHA, Allan AC,

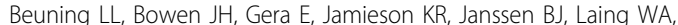
McArtney S, Nain B, Ross GS, Snowden KC, Souleyre EJF, Walton EF, Yauk YK: Analyses of expressed sequence tags from apple. Plant Physiol 2006, 141:147-166

25. Park S, Sugimoto N, Larson MD, Beaudry R, van Nocker S: Identification of genes with potential role in apple fruit development and biochemistry through large-scale statistical analysis of expressed sequence tags. Plant Physiol 2006, 141:811-824.

26. Moore S, Vrebalov J, Payton P, Giovannoni J: Use of genomics tools to isolate key ripening genes and analyse fruit maturation in tomato. $J$ Ex Bot 2002, 53:2023-2030.

27. Alba R, Fei Z, Payton P, Liu Y, Moore SL, Debbie P, Cohn J, D'Ascenzo M Gordon JS, Rose JKC, Martin G, Tanksley SD, Bouzayen M, Jahn MM, Giovannoni J: ESTs, cDNA microarrays, and gene expression profiling: tools for dissecting plant physiology and development. The Plant Journal 2004, 39:697-714. 
28. Alba R, Payton P. Fei Z, McQuinn R, Debbie P, Martin GB, Tanksley SD, Giovannoni JJ: Transcriptome and selected metabolite analyses reveal multiple points of ethylene control during tomato fruit development Plant Cell 2005, 17:2954-2965.

29. Wilkinson JQ, Lanahan MB, Yen H-C, Giovannoni JJ, Klee HJ: An ethyleneinducible component of signal transduction encoded by Never-ripe. Science 1995, 270:7807-1809.

30. Sisler EC, Serek M: Inhibitors of ethylene responses in plants at the receptor level: recent developments. Physiologia Plant 1997, 100:577-582.

31. Zeng Y, Yang T: RNA isolation from highly viscous samples rich in polyphenols and polysaccharides. Plant Miol Biol Rep 2002, 20:417a-417e.

32. Griffiths A, Barry C, Alpuche-Soils A, Grierson D: Ethylene and developmental signals regulate expression of lipoxygenase genes during tomato fruit ripening. J Ex Bot 1999, 50:793-798.

33. Fei Z, Tang X, Alba R, Payton P, Giovannoni J: Tomato Expression Database (TED) - An Interactive Management Tool for Tomato Expression Profiling Data. Procedings of the Computational Systems Bioinformatics CSB 2003, 424-425.

34. Fei Z, Tang X, Alba R, Giovannoni J: Tomato expression database (TED): a suite of data presentation and analysis tools. Nuc Acid Res 2006, 34 D766-D770.

35. Naidoo S, Denby KJ, Berger DK: Microarray experiments: considerations for experimental design. South African J of Sci 2005, 101:347-354.

36. Simon R, Lam A, Li M-C, Ngan M, Menenzes S, Zhao Y: Analysis of Gene Expression Data Using BRB-Array Tools. Cancer Informatics 2007, 2:11-17.

37. Herrero J, Al-Shahrour F, Diaz-Uriarte R, Mateos A, Vaquerizas JM, Santoyo J, Dopazo J: GEPAS: a web-based resource for microarray gene expression data analysis. Nuc Acids Res 2003, 31:3461-3467.

38. Herrero J, Valencia A, Dopazo J: A hierarchical unsupervised growing neural network for clustering gene expression patterns. Bioinformatics 2001, 17:126-136.

39. Moore S, Payton P, Wright M, Tanksley S, Giovannoni J: Utilization of tomato microarrays for comparative gene expression analysis in the Solanaceae. J Ex Bot 2005, 56:2885-2895.

40. Nishiyama K, Guis M, Rose JCK, Kubo Y, Bennett KA, Wangjin L, Kato K, Ushijima K, Nakano R, Inaba A, Bouzayen M, Latche A, Pech JC, Bennett AB: Ethylene regulation of fruit softening and cell wall disassembly in Charentais melon. J Ex Bot 2007, 58:1281-1290.

41. Chen G, Alexander L, Greirson D: Constitutive expression of ElL-like transcription factor partially restores ripening in the ethylene-insensitive Nr tomato mutant. J Ex Bot 2004, 55:1491-1497.

42. Solano R, Stepanova A, Chao Q, Ecker JR: Nuclear events in ethylene signalling: a transcriptional cascade mediated by ETHYLENEINSENSITIVE3 and ETHYLENE-RESPONSE FACTOR1. Genes and Dev 1998, 12:3703-3714.

43. Wang A, Tan D, Takahashi A, Li TZ, Harada T: MdERFs, two ethyleneresponse factors involved in apple fruit ripening. J Ex Bot 2007, 58:3743-3748.

44. Rose JKC, Lee $H H$, Bennett AB: Expression of a divergent expansin gene is fruit-specific and ripening-regulated. Proc Natl Acad Sci 1997, 94:5955-5960.

45. Rose JKC, Hadfield KA, Labavitch JM, Bennett AB: Temporal sequence of cell wall disassembly in rapidly ripening melon fruit. Plant Physiol 1998, 117:345-361.

46. Powell ALT, Kalamaki MS, Kurien PA, Guerrieri S, Bennett AB: Simultaneous transgenic suppression of LePG and LeExp1 influences fruit texture and juice viscosity in a fresh market tomato variety. J Agric Food Chem 2003, 51:7450-7455.

47. Causier B, Kieffer M, Davies B: MADS-Box genes reach maturity. Science 2002, 296:275-276

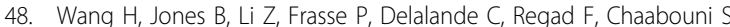
Latché A, Pech JC, Bouzayen M: The tomato Aux/IAA transcription factor IAA9 is involved in fruit development and leaf morphogenesis. Plant Cell 2005, 17:2676-2692.

49. Vrebalov J, Ruezinsky D, Padmanabhan V, White R, Medrano D, Drake R, Schuch W, Giovannoni J: A MADS-Box gene necessary for fruit ripening at the tomato Ripening-Inhibitor (Rin) locus. Science 2002, 296:343-346.

50. Folter S, Busscher J, Colombo L, Losa A, Angenent CA: Transcript profiling of factor genes during silique development in Arabidopsis. Plant Mol Biol 2004, 56:351-366.
51. Yao J-L, Dong $Y-H$, Morris BAM: Parthenocarpic apple fruit production conferred by transposon insertion mutations in a MADS-box transcription factors. Proc Natl Acad Sci 2001, 98:1306-1311.

52. Reichmann JL, Heard J, Martin G, Reuber L, Jiang C, Keddie J, Adam L, Pineda O, Ratcliffe OJ, Samaha RR, Creelman R, Pilgrim L, Broun P, Zhang JZ, Ghandehari D, Sherman BK, Yu G-L: Arabidopsis transcription factors: genome-wide comparative analysis among eukaryotes. Science 2000, 290:2105-2110.

53. Levi A, Davis A, Hernandez A, Wechter P, Thimmapuram J, Trebitsh T, Tadmor $Y$, Katzir N, Portnoy $V$, King S: Genes expressed during the development and ripening of watermelon fruit. Plant Cell Rep 2006, 25:1233-1245

54. Fei Z, Tang X, Alba RM, White JA, Ronning CM, Martin GB, Tanksley SD, Giovannoni JJ: Comprehensive EST analysis of tomato and comparative genomics of fruit ripening. The Plant J 2004, 40:47-59.

55. Aharoni A, De Vos CHR, Wein M, Sun Z, Greco R, Kroon A, Mol JNM, O'Connel AP: The strawberry FaMYB1 transcription factor suppresses anthocyanin and flavonol accumulation in transgenic tobacco. The Plant J 2001, 28:319-332

56. Eriksson EM, Bovy A, Manning K, Harrison L, Andrews J, De Silva J, Tucker GA, Seymour G: Effect of the colorless non-ripening mutation on cell wall biochemistry and gene expression during tomato fruit development and ripening. Plant Physiol 2004, 136:4184-4197.

57. Tieman DM, Taylor MG, Ciardi JA, Klee J: The tomato ethylene receptors NR and LeETR4 are negative regulators of ethylene response and exhibit functional compensation within a multigene family. Proc Natl Acad SC 2000, 97:5663-5668.

58. Metzker ML: Sequencing technologies - the next generation. Nature Rev Genet 2010, 11:31-44.

59. Young MD, Wakefield MJ: Gene ontology analysis for RNA-seq: accounting for selection bias. Genome Biology 2010, 11:R14.

60. Velasco R, Zharkikh A, Affourtit J, Dhingra A, Cestaro A, Kalyanaraman A, Fontana P, Bhatnagar SK, Troggio M, Pruss D, Salvi S, Pindo M, Baldi P, Castelletti S, Cavaiuolo M, Coppola G, Costa F, Cova V, Dal Ri A, Goremykin V, Komjanc M, Longhi S, Magnago P, Malacarne G, Malnoy M, Micheletti D, Moretto M, Perazzolli M, Si-Ammour A, Vezzulli S, Zini E, Eldredge G, Fitzgerald LM, Gutin N, Lanchbury J, Macalma T, Mitchell JT, Reid J, Wardell B, Kodira C, Chen Z, Desany B, Niazi F, Palmer M, Koepke T, Jiwan D, Schaeffer S, Krishnan V, Wu C, Chu VT, King ST, Vick J, Tao Q, Mraz A, Stormo A, Stormo K, Bogden R, Ederle D, Stella A, Vecchietti A, Kater MM, Masiero S, Lasserre $P$, Lespinasse $Y$, Allan AC, Bus V, Chagné D, Crowhurst RN, Gleave AP, Lavezzo E, Fawcett JA, Proost S, Rouzé P, Sterck L, Toppo S, Lazzari B, Hellens RP, Durel C-E, Gutin A, Bumgarner RE, Gardiner SE, Skolnick M, Egholm M, Van de Peer Y, Salamini F, Viola R: The genome of the domesticated apple (Malus $\times$ domestica Borkh.). Nature Genet 2010, 42(10):833-839.

doi:10.1186/1471-2229-10-229

Cite this article as: Costa et al:: Use of homologous and heterologous gene expression profiling tools to characterize transcription dynamics during apple fruit maturation and ripening. BMC Plant Biology 2010 $10: 229$

\section{Submit your next manuscript to BioMed Central and take full advantage of:}

- Convenient online submission

- Thorough peer review

- No space constraints or color figure charges

- Immediate publication on acceptance

- Inclusion in PubMed, CAS, Scopus and Google Scholar

- Research which is freely available for redistribution

Submit your manuscript at www.biomedcentral.com/submit
C Biomed Central 